\title{
TU/e Emonowe

\section{Surface directed phase separation of semiconductor ferroelectric polymer blends and their use in non-volatile memories}

\section{Citation for published version (APA):}

Breemen, van, A. J. J. M., Zaba, T., Khikhlovskyi, V., Michels, J. J., Janssen, R. A. J., Kemerink, M., \& Gelinck, G. (2015). Surface directed phase separation of semiconductor ferroelectric polymer blends and their use in non-volatile memories. Advanced Functional Materials, 25(2), 278-286. https://doi.org/10.1002/adfm.201401896

DOI:

10.1002/adfm.201401896

Document status and date:

Published: 01/01/2015

\section{Document Version:}

Publisher's PDF, also known as Version of Record (includes final page, issue and volume numbers)

\section{Please check the document version of this publication:}

- A submitted manuscript is the version of the article upon submission and before peer-review. There can be important differences between the submitted version and the official published version of record. People interested in the research are advised to contact the author for the final version of the publication, or visit the DOI to the publisher's website.

- The final author version and the galley proof are versions of the publication after peer review.

- The final published version features the final layout of the paper including the volume, issue and page numbers.

Link to publication

\footnotetext{
General rights

- You may freely distribute the URL identifying the publication in the public portal. follow below link for the End User Agreement:

www.tue.nl/taverne

\section{Take down policy}

If you believe that this document breaches copyright please contact us at:

openaccess@tue.nl

providing details and we will investigate your claim.
}

Copyright and moral rights for the publications made accessible in the public portal are retained by the authors and/or other copyright owners and it is a condition of accessing publications that users recognise and abide by the legal requirements associated with these rights.

- Users may download and print one copy of any publication from the public portal for the purpose of private study or research.

- You may not further distribute the material or use it for any profit-making activity or commercial gain

If the publication is distributed under the terms of Article $25 \mathrm{fa}$ of the Dutch Copyright Act, indicated by the "Taverne" license above, please 


\title{
Surface Directed Phase Separation of Semiconductor Ferroelectric Polymer Blends and their Use in Non-Volatile Memories
}

\author{
Albert van Breemen,* Tomasz Zaba, Vsevolod Khikhlovskyi, Jasper Michels, Rene Janssen, \\ Martijn Kemerink, and Gerwin Gelinck
}

The polymer phase separation of P(VDF-TrFE):F8BT blends is studied in detail. Its morphology is key to the operation and performance of memory diodes. In this study, it is demonstrated that it is possible to direct the semiconducting domains of a phase-separating mixture of P(VDF-TrFE) and F8BT in a thin film into a highly ordered 2D lattice by means of surface directed phase separation. Numerical simulation of the surface-controlled de-mixing process provides insight in the ability of the substrate pattern to direct the phase separation, and hence the regularity of the domain pattern in the final dry blend layer. By optimizing the ratio of the blend components, the number of electrically active semiconductor domains is maximized. Pattern replication on a cm-scale is achieved, and improved functional device performance is demonstrated in the form of a 10-fold increase of the ON-current and a sixfold increase in current modulation. This approach therefore provides a simple and scalable means to higher density integration, the ultimate target being a single semiconducting domain per memory cell.

\section{Introduction}

Solution-processed polymer semiconductors offer the possibility to mix together active components having markedly different electronic and/or optical properties in a common solvent. ${ }^{[1]}$ Upon solvent extraction, the polymers typically demix and a thin film with a phase separated morphology is formed. Previously reported work in the field of photovoltaics, ${ }^{[2]}$ light emitting diodes ${ }^{[3]}$ and transistors ${ }^{[4]}$ provides clear examples of the efficiency of this approach, as well as some of its limitations. Recently, ${ }^{\left[{ }^{[}\right]}$Asadi et al. used a phase separated blend of semiconducting and ferroelectric polymer to make polymer

Dr. A. J. J. M. van Breemen, T. Zaba, V. Khikhlovskyi,

Dr. J. J. Michels, Dr. G. H. Gelinck

Holst Centre/TNO

High Tech Campus 31, Eindhoven, The Netherlands

E-mail: albert.vanbreemen@tno.nl

V. Khikhlovskyi, Prof. R. A. J. Janssen, Dr. M. Kemerink

Eindhoven University of Technology, P.O. Box 513

5600, MB, Eindhoven, The Netherlands

Prof. M. Kemerink

Department of Physics

Chemistry and Biology (IFM)

Linköping University

SE-58183, Sweden

DOI: 10.1002/adfm.201401896 non-volatile memories. In all these device types, the electronic characteristics depends critically on the final morphology, and better insights into the phase separation, mechanism, and control thereof will ultimately enhance our ability to engineer greater functionality into future organic electronics systems.

Bulk demixing of binary polymer mixtures has been studied extensively during the last decades and is reasonably well understood. ${ }^{[6]}$ Most previous studies focused on de-mixing phenomena in polymer melts. In organic electronics applications, however, thin films are prepared by a sudden extraction of a solvent. Due to their intrinsic immiscibility, polymer mixtures typically de-mix during solvent evaporation. The resulting phaseseparated morphology may be far from thermodynamic equilibrium, and relaxation toward equilibrium may be hindered by kinetic barriers formed by the nonequilibrium phase morphology. Furthermore, surface effects can play a role. Phase separation in bulk mixtures commonly leads to an isotropic, disordered morphology of the coexisting phases, whereas the influence of a surface may lead to preferential segregation of one of the components near the surface, for instance in the form of a wetting layer.

In Asadi's new polymer non-volatile memory, the blend of semiconducting and ferroelectric polymer is sandwiched between two metal electrodes..$^{[5]}$ The ferroelectric polymer provides the binary state and data retention, whereas the semiconducting polymer domains provides the means to probe that state via an electrical current. More specifically, the polarization-induced field of the ferroelectric polymer modulates the injection barrier at the semiconductor-electrode interface leading to bistable current switching..$^{[7]}$ Numerical calculations indicate that the stray field of the polarized ferroelectric laterally permeates at most a few tens of $\mathrm{nm}$ into the semiconductor. ${ }^{[8]}$ Hence, control over the semiconductor domain size is crucial. It was shown ${ }^{[9]}$ that the solvent-processed phase separated blend comprised of disk-shaped submicrometer sized domains of the semiconducting polymer (i.e., poly(3-hexylthiophene) (P3HT)), dispersed in a matrix of the ferroelectric copolymer poly(vinylidenefluoride-co-trifluoroethylene) (P(VDF-TrFE). A similar morphology was observed when P(VDF-TrFE) was mixed with other polymeric semiconductors such as 
poly(9,9'-dioctyl fluorene) (PFO) ${ }^{[10]}$ and poly[(9,9-di- $n$-octylfluorenyl-2,7-diyl)-alt-(benzo[2,1,3]thia-diazol-4,8-diyl)] (F8BT $)^{[11]}$ as well as molecular semiconductors such as [6,6]-phenylC61-butyric acid methyl ester (PCBM) ${ }^{[12]}$ It has been shown that liquid phase de-mixing of the blend components occurs via surface-directed spinodal decomposition during solution casting. ${ }^{[13]}$ Surface tension differences determine to what extent one of the phases is preferred at an interface, and thus whether surface-directed stratification plays a (dominant) role in establishing the final phase geometry. ${ }^{[14-17]}$ In all these previous studies the final blend morphology is characterized by a random distribution of semiconductor domains, both in domain size as well as location. However, size, shape, distribution, percolation, and orientation of the semiconducting domains have been shown to determine the ultimate performance of the device. ${ }^{[7,8]}$ Precise control over the morphology of phase separated blends is therefore highly desirable in order to achieve improved functionality. Moreover, it will facilitate further miniaturization of these memory diodes to smaller feature size and/or higher integration density.

In this study we demonstrate that it is possible to direct the semiconducting domains of a phase-separating mixture of $\mathrm{P}(\mathrm{VDF}-\mathrm{TrFE})$ and F8BT in a thin film into a highly ordered 2D lattice by means of surface directed phase separation. Numerical simulation of the surface-controlled de-mixing process provides insight in the ability of the substrate pattern to direct the phase separation, and hence the regularity of the domain pattern in the final dry blend layer. Pattern replication on a cm-scale is achieved, and improved functional device performance is demonstrated in the form of a 10-fold increase of the ON-current and a sixfold increase in current modulation. This approach therefore provides a simple and scalable means to higher density integration, the ultimate target being a single semiconducting domain per memory cell.

\section{Results and Discussion}

\subsection{Blend Layer Processing on Non-Patterned Substrates}

The molecular structures of the polymer materials used in this work are shown in Figure 1a. Figure 1b shows schematically the cross-section of a phase separated blend of P(VDF-TrFE) and F8BT sandwiched between the two metallic electrodes. As (a)

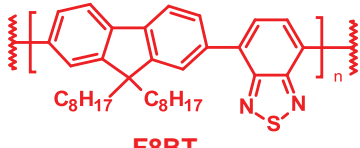

F8BT

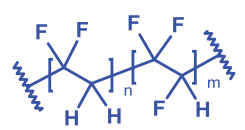

P(VDF-TrFE) (b)

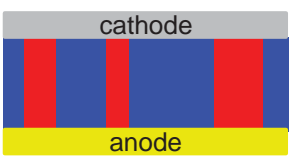

Figure 1. a) Chemical structures of the semiconducting polymer F8BT and ferroelectric polymer P(VDF-TrFE); b) schematic representation of a phase separated blend memory diode consisting of F8BT domains (red) in a ferroelectric P(VDF-TrFE) matrix (blue).
Table 1. Surface- and interfacial energies of the individual components of a blend consisting of solvent (cyclohexanone), P(VDF-TrFE), and $\mathrm{F} 8 \mathrm{BT}$, processed on a gold substrate, either or not covered with an $\mathrm{OH}$-terminated SAM.

\begin{tabular}{lccccc}
\hline & Au & OH-SAM & solvent & P(VDF-TrFE $)$ & F8BT \\
\hline$\gamma(\mathrm{mN} / \mathrm{m})$ & 53.3 & 75.1 & 34.0 & 29.3 & 32.8 \\
$\gamma^{d}(\mathrm{mN} / \mathrm{m})$ & 44.7 & 44.4 & 31.4 & 24.4 & 32.6 \\
$\gamma^{p}(\mathrm{mN} / \mathrm{m})$ & 8.6 & 30.7 & 2.6 & 4.9 & 0.2 \\
$\gamma_{\text {I-Au }}(\mathrm{mN} / \mathrm{m})$ & 0 & - & 2.9 & 3.6 & 7.1 \\
$\gamma_{\text {I-OH SAM }}(\mathrm{mN} / \mathrm{m})$ & - & 0 & 16.5 & 14.1 & 26.8 \\
\hline
\end{tabular}

bottom electrode are used: i) gold $(\mathrm{Au})$ and ii) $\mathrm{Au}$ fully passivated with a monolayer of 11-mercapto-1-undecanol (OH-SAM, Figure $3 \mathrm{~b}$ ). Blend films with $h \approx 250 \mathrm{~nm}$ are spin-coated on bare $\mathrm{Au}$ or patterned OH-SAM-passivated $\mathrm{Au}$ electrodes and subsequently annealed at $135^{\circ} \mathrm{C}$ for 1 hour to facilitate development of the ferroelectric $ß$-phase of P(VDF-TrFE).$^{[18]}$ The diodes are finished by evaporating a $100 \mathrm{~nm}$ top barium/aluminum (Ba/Al) cathode through a shadow mask.

Table 1 lists the measured total surface energies $(\gamma)$ and their disperse $\left(\gamma^{d}\right)$ and polar $\left(\gamma^{p}\right)$ contributions, together with the calculated interfacial energies $\left(\gamma_{I-i}\right)$ for all blend components and substrates under consideration. The method used for obtaining $\gamma^{d}$ and $\gamma^{p}$ is the one proposed by Owens, Wendt, Rabel, and Kaelbe, ${ }^{[19,20]}$ whereas the interfacial tensions are calculated according to the Fowkes procedure. ${ }^{[21]}$ The preference of a given component for a certain substrate depends on the interfacial energy between the two: the lower the interfacial energy, the more the component is preferred at the given substrate. From this it can be inferred that P(VDF-TrFE) is preferred at $\mathrm{Au}$ and OH-SAM interfaces (Table 1). Here, specific coordination between substrate and substance (e.g., gold and sulfur) is neglected.

Figure 2 (top row) shows the surface morphology of films spin-coated on bare Au (Figure 2b,d), and on OH-SAM monolayer-covered Au substrates (Figure 2c,e), as measured using AFM. We used two different weight ratio's, i.e., a 9:1 and 4:1 (w/w) P(VDF-TrFE):F8BT blend ratio respectively. In all cases, disk-like entities of the minor component (i.e., F8BT) embedded in a matrix of the major component (i.e., $\mathrm{P}(\mathrm{VDF}-\mathrm{TrFE})$ ) are observed, similar to the morphology previously observed for blends of $\mathrm{P}(\mathrm{VDF}-\mathrm{TrFE}): \mathrm{P} \mathrm{HT}^{[9]}$ and $\mathrm{P}(\mathrm{VDF}-\mathrm{TrFE}): \mathrm{PFO} \cdot{ }^{[10,13]}$ Changing the surface of the underlying gold substrate, by means of OH-SAM, has a strong influence on the phase separation. The OH-SAM-treated substrate shows smaller F8BT disks. The 9:1 blend film processed on bare Au (Figure $2 \mathrm{~b}$ top row) reveals two type of semiconductor domains. $40 \%\left(10\right.$ per $\left.100 \mathrm{~mm}^{2}\right)$ of the F8BT domains have a concave top surface (F8BT curves inward) and an average diameter of $500 \mathrm{~nm}$, whereas $60 \%$ has a convex top surface, that is, F8BT is protuberant. The convex domains typically have a larger average diameter of $800 \mathrm{~nm}$. On OH-SAM passivated Au (Figure 2c top row) the 9:1 blend film shows a large increase in number density of both the concave and convex domain types to 40 and 70 per $100 \mathrm{\mu m}^{2}$, respectively. The average domain size of the concave domains remains more or less constant, whereas that of the convex domains is reduced to $600 \mathrm{~nm}$. Increasing the relative amount of F8BT by going to a $4: 1$ blend ratio results 

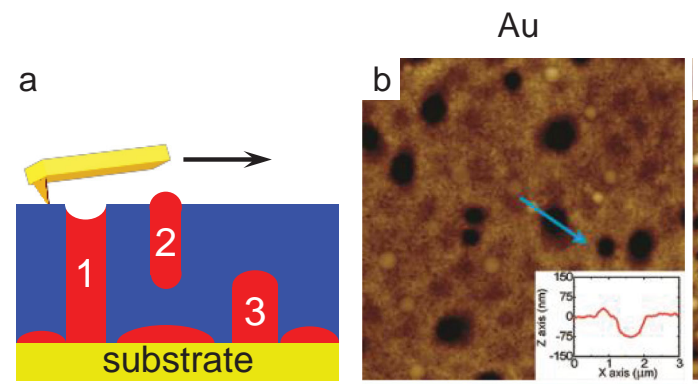

$\mathrm{Au}+\mathrm{OH}-\mathrm{SAM}$
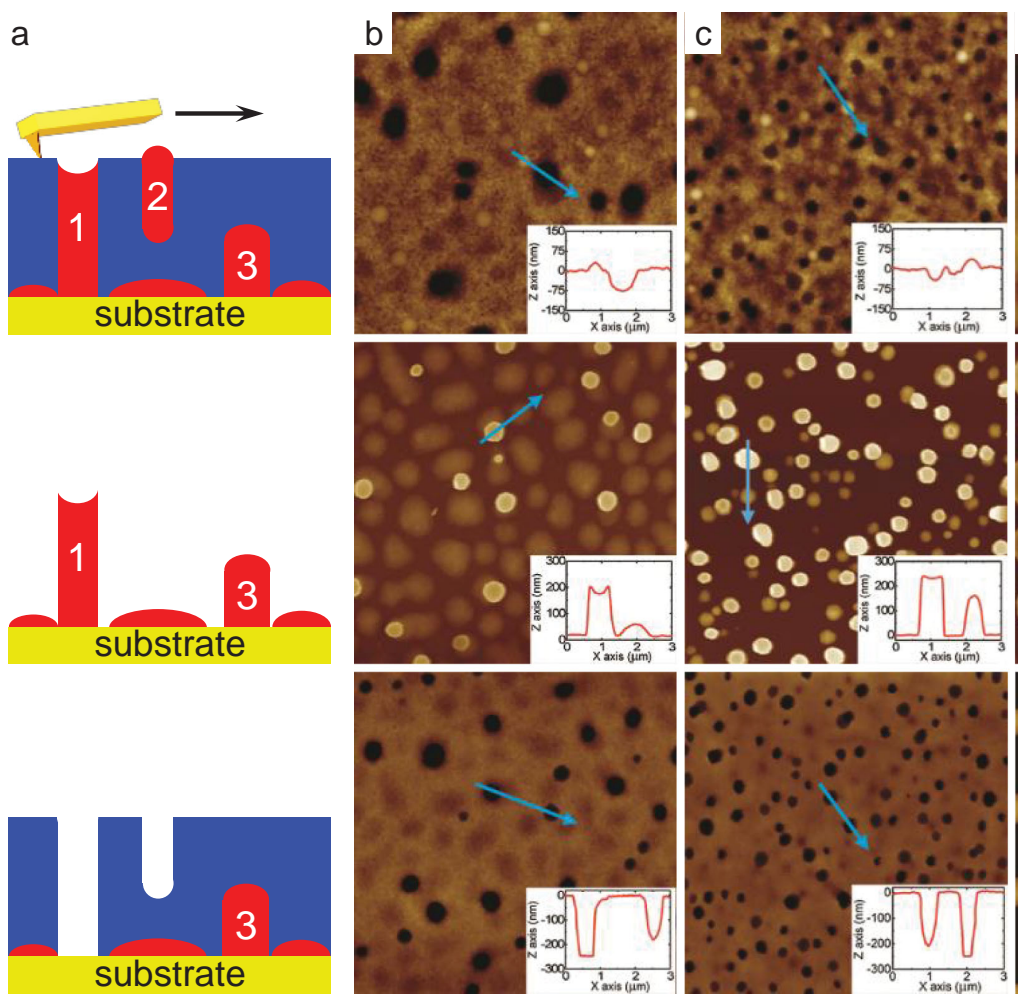

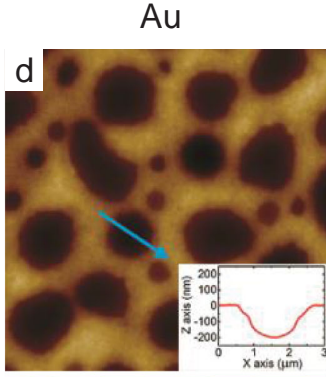

$\mathrm{Au}+\mathrm{OH}-\mathrm{SAM}$
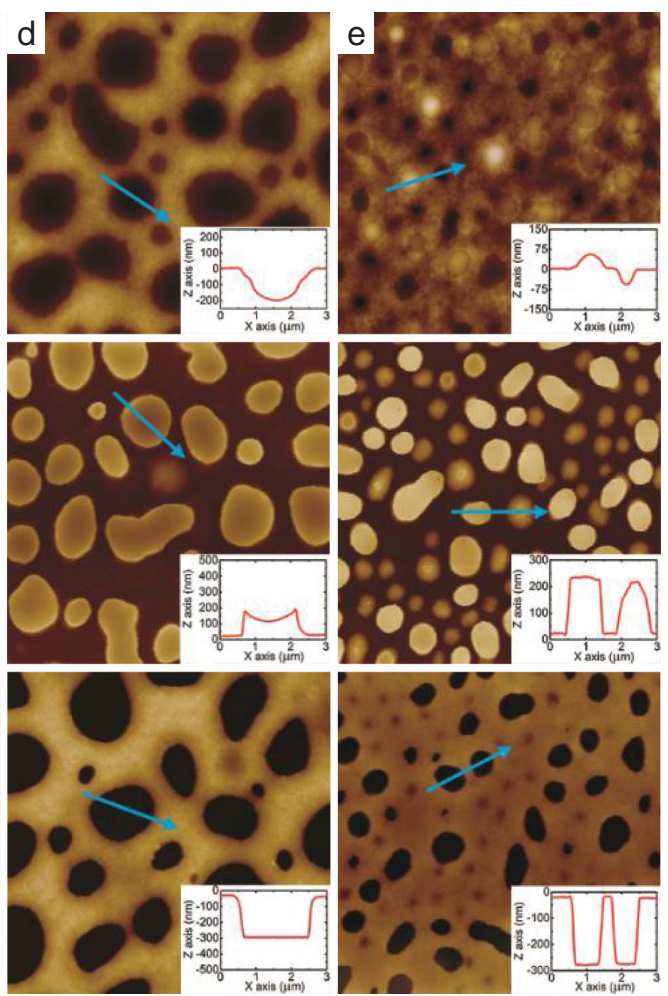

Figure 2. a) Schematic representation of the films studied. Top row: as processed blend. Middle row: the ferroelectric was selectively removed. Bottom row: semiconductor was selectively removed. See text for more experimental details on the procedure to selectively remove a single polymer component from the blend. b) AFM images $(10 \mu \mathrm{m} \times 10 \mu \mathrm{m})$ of 9:1 w/w blend deposited on an Au substrate. c) 9:1 w/w blend deposited on an Au substrate covered with OH-SAM. d) 4:1 w/w blend deposited on Au electrode. e) 4:1 w/w blend deposited on an Au substrate covered with OH-SAM. Insets indicate line sections over the blend shown with blue arrows.

in almost exclusively convex, F8BT domains with large diameter $(\langle d\rangle \approx 2 \mu \mathrm{m})$ on bare Au (Figure $2 \mathrm{~d}$ ). OH-SAM passivation again leads to a suppression of the average size of the convex domains $(\langle d\rangle \approx 1.2 \mu \mathrm{m})$, at a significantly increased number density of 45 per $100 \mu^{2}$.

To gain further information on the morphology throughout the blend film, we selectively removed one of the polymers from the blend films. Dimethylsulfoxide (DMSO) was found to selectively dissolve P(VDF-TrFE), whereas toluene could be used to dissolve F8BT. Figure 2 shows AFM topography images obtained after the films have been treated with DMSO (middle row) and toluene (bottom row), respectively. The images in the middle row reveal pillar-, as well as drop-like F8BT domains. These are labelled as "1" and " 3 " in Figure 2a. The images in the bottom row show assemblies of depressions of different depths in the P(VDF-TrFE) matrix. Putting these images together, we can distinguish three types of F8BT domains: "bridging" (type-1), "floating" (type-2), and "buried" (type 3) domains. This is illustrated in Figure 2a. Line scans consistently reveal the top surface of the type- 1 domains to be convex, whereas a concave top surface is encountered for the type- 2 and type- 3 domains. Line scans across the depressions originally occupied by type- 1 and type- 2 domains reveal the flat bottom surface of the substrate. Finally, we see evidence of a very thin (40 $\mathrm{nm}$ or less) F8BT wetting layer in the 9:1 blend processed on bare Au. This wetting layer is absent in the $\mathrm{OH}-\mathrm{SAM}$ treated substrate. We therefore attribute the formation of the wetting layer to a specific coordinative interaction between the sulfur atoms of the F8BT and Au, a phenomenon also observed for a similar sulfur-containing polymeric semiconductor on $\mathrm{Au}$. $^{[22]}$

Only the type- 1 F8BT domains are electrically active, ${ }^{[8]}$ as they bridge both electrodes in a memory device. Quantitative analysis reveals that the number density of type- 1 domains increases from 15 to 65 per $100 \mu^{2}$ upon OH-SAM passivation. Increasing the relative amount of F8BT by going from a 9:1 to a $4: 1$ blend ratio, results in large $(\langle d\rangle \approx 2 \mu \mathrm{m})$ F8BT droplets on bare Au (Figure 2d), as sufficient semiconductor is now provided for the wetting layer to absorb all material. Although in this situation virtually all domains are "bridging", and therefore electrically active, such large domains are to be avoided. Numerical calculations and conductive AFM experiments ${ }^{[8]}$ have shown that the stray field of the polarized ferroelectric laterally permeates at most a few tens of nm into the semiconductor. Hence, the current predominantly flows through the perimeter of the semiconducting domains ${ }^{[8]}$ and it is preferred 
Table 2. Number density and average diameter of type-1 F8BT domains vs electrode and blend ratio, as estimated from AFM images (Figure 2 and Figure 3 ). Mean value of $I_{\mathrm{ON}}$ and $I_{\mathrm{ON}} / I_{\mathrm{OFF}}$ ratios measured at a bias of $+6 \mathrm{~V}$ of 25 diodes fabricated with a P(VDF-TrFE):F8BT 9:1 or 4:1 w/w blend using either a patterned or non-patterned Au bottom electrode.

\begin{tabular}{lccccc}
\hline $\begin{array}{l}\text { bottom } \\
\text { electrode }\end{array}$ & $\begin{array}{c}\text { blend ratio } \\
(\mathrm{w} / \mathrm{w})\end{array}$ & $\begin{array}{c}\text { \# type- } 1 \\
\left(\text { per } 100 \mu \mathrm{m}^{2}\right)\end{array}$ & $\begin{array}{c}<d> \\
{[\mathrm{nm}]}\end{array}$ & $\begin{array}{c}I_{\text {ON }} \\
{[\mu \mathrm{A}]}\end{array}$ & $I_{\text {ON }} / I_{\text {OFF }}$ \\
\hline bare Au & $9: 1$ & 15 & $800 \pm 150$ & $0.60 \pm 0.04$ & $1500 \pm 90$ \\
bare Au & $4: 1$ & 27 & $2000 \pm 350$ & $0.69 \pm 0.04$ & $1800 \pm 100$ \\
OH-SAM & $9: 1$ & 65 & $600 \pm 100$ & - & - \\
OH-SAM & $4: 1$ & 45 & $1200 \pm 200$ & - & - \\
$\mu$ CP OH-SAM & $9: 1$ & 14 & $500 \pm 50$ & $0.63 \pm 0.08$ & $1700 \pm 250$ \\
$\mu$ CP OH-SAM & $4: 1$ & 100 & $600 \pm 75$ & $6.02 \pm 0.34$ & $8900 \pm 380$ \\
\hline
\end{tabular}

to have more domains with a smaller diameter. Au passivation with OH-SAM leads to suppression of the average size of the type- 1 domains $(\langle d\rangle \approx 1.2 \mu \mathrm{m})$, at a number density of 45 per $100 \mu \mathrm{m}^{2}$. Nevertheless, some material remains inactive due to the occurrence of type- 3 features. As for device performance the number and diameter of the type-1 F8BT domains are most relevant, we list these parameters for the different films studied in Table 2.

\subsection{Blend Layer Processing on Substrates with Patterned SAMs}

It has previously been shown that the domains of a phase-separating mixture of polymers in a thin film can be guided into periodic structures by a surface with a pre-patterned variation of surface energies. ${ }^{[23,24]}$ This pioneering work focused on the methodology of this approach rather than incorporating these patterned layers in electronic devices. Morphology control by surface directed phase separation was explored in organic light emitting diodes, ${ }^{[25-27]}$ photovoltaics ${ }^{[28]}$ and thin film transistors. ${ }^{[29,30]}$ Next, we show that this bottom-up approach also works for ferroelectric-semiconductor blends.

As mentioned above, F8BT has a strong coordinative interaction towards $\mathrm{Au}$, which can be nullified by monolayer passivation of the gold surface. In addition, the calculated interfacial energies between SAM-passivated gold and the individual blend components (Table 1), reveal that $\mathrm{P}(\mathrm{VDF}-\mathrm{TrFE})$ is preferred at an OH-SAM-passivated Au substrate. These findings can be used to gain better control over the morphology of solution processed P(VDF-TrFE):F8BT blends. The strong F8BT-Au interaction is utilized to allow for adsorption of the semiconductor onto designated areas by geometrically controlled $\mathrm{OH}-\mathrm{SAM}$-passivation of the gold substrate prior to casting the P(VDF-TrFE):F8BT blend solutions (Figure 3). Type-1 F8BT domains are therefore only in physical contact with bare gold, and possible effects of the $\mathrm{OH}$-SAM changing the workfunction of the gold electrodes are therefore not relevant in this study.

The OH-SAM is deposited locally using micro-contact printing $^{[31,32]}(\mu \mathrm{CP})$. Figure $3 \mathrm{a}$ shows a schematic representation of the patterning process of the Au electrode, together with the dimensions of the features of the PDMS stamp. Figure $3 b$ represents a schematic side view of a $\mu \mathrm{CP}$ Au electrode. OH-SAM is deposited everywhere except for small circular areas. These circular areas have a nominal diameter of $500 \mathrm{~nm}$ and are periodically placed on a rectangular grid with a periodicity of $1 \mu \mathrm{m}$. The molecular structure of the OH-SAM is

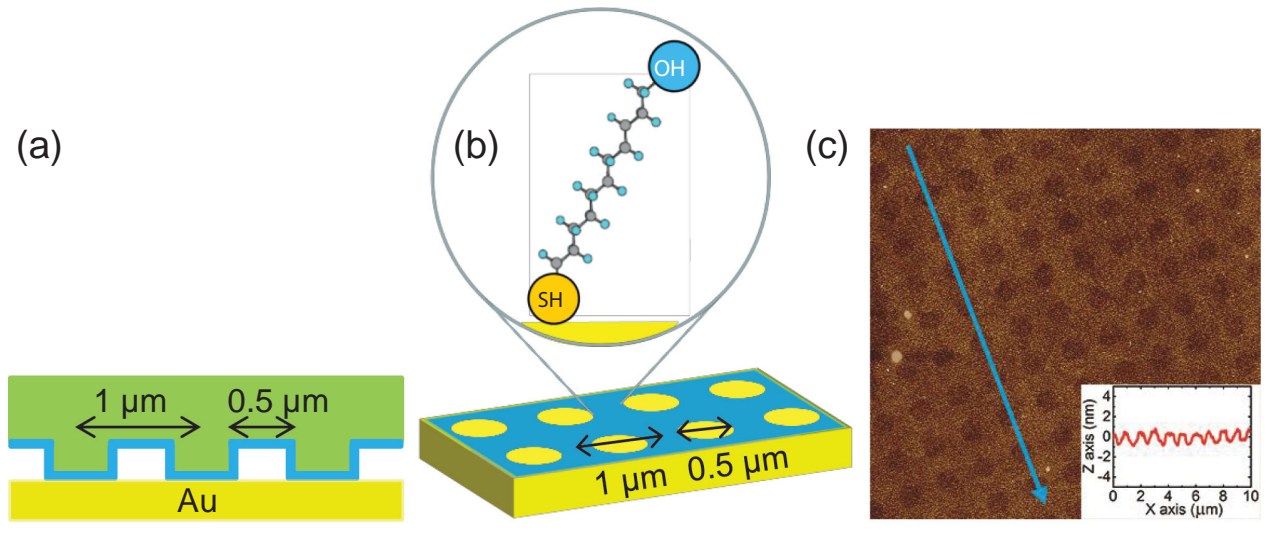

(d)

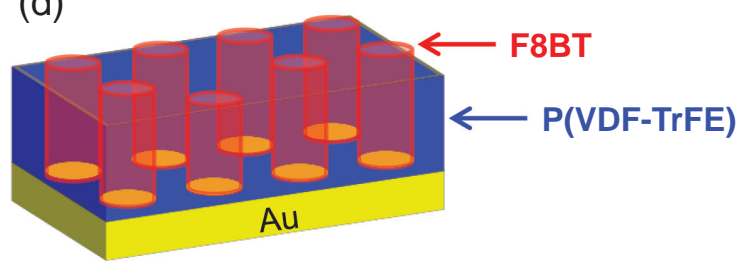

Figure 3. a) Schematic representation of the $\mu \mathrm{CP}$ process using a PDMS stamp featuring a rectangular array of circular posts with a diameter of $0.5 \mu \mathrm{m}$ and a pitch of $1 \mu \mathrm{m}$. b) Schematic representation of geometrically controlled OH-SAM passivation of the Au substrate. c) AFM image (10 $\mu \mathrm{m} \times 10 \mu \mathrm{m})$ of Au substrate micro-contact printed with OH-SAM. Inset: line scan of the patterned substrate taken at the position indicated by the blue arrow. d) Geometrically controlled phase separation induced by local OH-SAM passivation of the Au substrate. The strong F8BT-Au interaction is utilized to allow for selective adsorption of the semiconductor onto the Au electrode. 


\section{P(VDF-TrFE):F8BT P(VDF-TrFE):F8BT 9:1 $4: 1$}
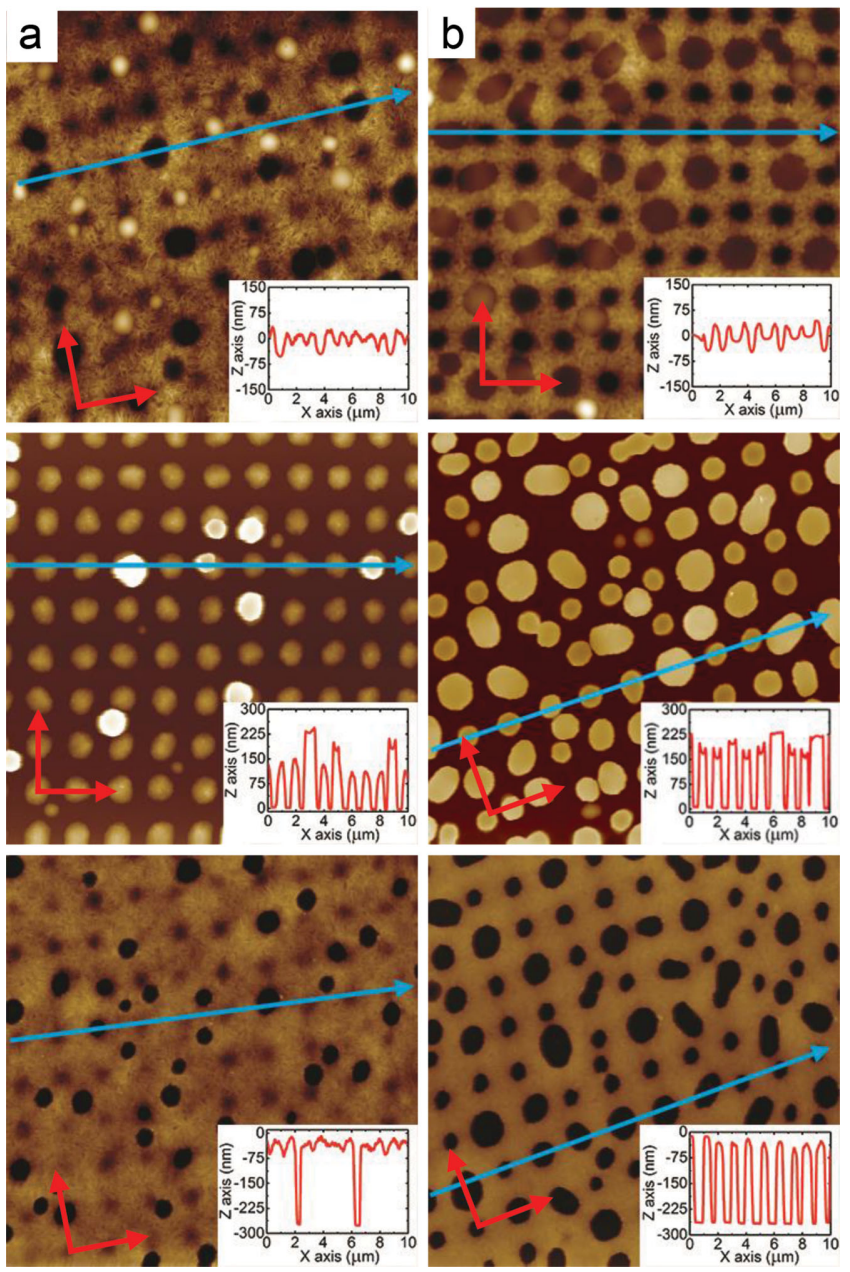

Figure 4. a) AFM images $(10 \mu \mathrm{m} \times 10 \mu \mathrm{m})$ of $\mathrm{P}(\mathrm{VDF}-\mathrm{TrFE}): \mathrm{F} 8 \mathrm{BT}(9: 1$ $\mathrm{w} / \mathrm{w}$ ) blend coated on $\mathrm{OH}-\mathrm{SAM}$ patterned $\mathrm{Au}$ electrode. Top panel: as processed blend. Middle panel: selectively removed P(VDF-TrFE). Bottom panel: selectively removed F8BT. Insets indicate line sections over the blend shown with blue arrows. b) Idem for P(VDF-TrFE):F8BT (4:1 w/w) blend.

also shown. Figure 3c shows the AFM topography image of the patterned Au electrode. The dark circular features in Figure 3c correspond to the bare $\mathrm{Au}$ areas, whereas the interstitial area is coated with OH-SAM. The average diameter of the circular features, as well as the center-to-center distance agree well with the expected values based on the stamp. Spreading of the OH-SAM ink is limited. The OH-SAM thickness as determined by AFM is $\approx 2 \mathrm{~nm}$, which is in good agreement with literature values. ${ }^{[33]}$ These results clearly demonstrate that this OH-SAM can be transferred to $\mathrm{Au}$ with excellent pattern replication using $\mu \mathrm{CP}$.

Figure 4 shows AFM topography images of the P(VDFTrFE):F8BT (9:1 w/w) and (4:1 w/w) blends spincoated on the $\mathrm{Au}$ substrates patterned with $\mathrm{OH}-\mathrm{SAM}$, together with images obtained after selective removal of one of the polymers from the blend films. Well-ordered 2D arrays of F8BT domains are observed that nicely replicate the $\mu \mathrm{CP}$ pattern. In fact, pattern replication was achieved over complete $\mathrm{cm}^{2}$-area samples, that is, much larger length scales than shown in the AFM images in Figure 4. Pattern fidelity is particularly good for the $9: 1 \mathrm{w} / \mathrm{w}$ blend. However, from the low average height $(\approx 100-150 \mathrm{~nm})$ of the F8BT domains compared to the blend film thickness of $250 \mathrm{~nm}$, we conclude that about $80 \%$ of the F8BT domains of the patterned 9:1 blend are of non-bridging type-3. This assessment is confirmed in the images with the F8BT selectively removed (bottom row) where only a small number of pits goes all the way down to the substrate.

Numerical modeling of the phase separation process (see below) predicts that the number of type-1 F8BT domains can increase by increasing the relative amount of F8BT. This is indeed experimentally confirmed by the AFM topography images of the 4:1 (w/w) blend (Figure 4b). Almost all F8BT domains have a height that closely matches the thickness of the as-processed blend film, implying that they are of type- 1 . Furthermore, the average lateral domain size of $0.5 \mu \mathrm{m}$ at the bottom of the film (lower panel Figure $4 \mathrm{~b}$ ) is close to the $\mu \mathrm{CP}$ pattern. These results demonstrate that local deposition of $\mathrm{OH}$-SAM by $\mu \mathrm{CP}$ patterning prior to blend deposition is a simple and powerful technique to influence the morphology and increase the number of electrically active type- 1 domains.

\subsection{Simulations}

Time-resolved numerical modeling of the phase separation process can provide highly valuable information on the origin of specific features of the phase morphology of semiconductor/ $\mathrm{P}(\mathrm{VDF}-\mathrm{TrFE})$ mixtures. Fluid phase spinodal decomposition of the solvent/P(VDF-TrFE)/F8BT ternary under evaporative conditions is modeled by a Cahn-Hilliard-Cook-deGennes type square gradient approximation. We refer to the Experimental section and the Supporting Information (SI) for more details regarding the modeling approach. Representation and discussion of the complete evolution of the microstructure is outside the scope of this paper. Here we resort to discussing one (and the same) single time simulation snapshot for both blend P(VDF-TrFE)/F8BT ratios on patterned and nonpatterned monolayers. The snapshot represents a transient stage in the coarsening regime which allows the study of critical features preserved in the dried film.

Figure 5 shows simulation results by representing top view, as well as 3D tilted view images of the phase separated solvent/ $\mathrm{P}(\mathrm{VDF}-\mathrm{TrFE})$ :F8BT morphology. The simulation results for a 9:1 blend ratio reproduce well the regular spacing of the F8BT domains on the areas without OH-SAM (Figure 4a). The contact line diameter is more or less equal to the diameter of the dot itself. This seemingly trivial observation suggests that the spinodal wavelength (which is an intrinsic feature of the blend at a given composition) is at least of the same order as the dot spacing of the substrate pattern and that gradient energy contributions are high enough to prevent break-up of transient F8BT-rich domains into smaller droplets residing on the same dot. In line with the observed morphology, the numerical model also reproduces that pattern replication of the 9:1 blend is slightly better than that of the 4:1 blend ratio. Experiments and simulations (Figure 4b,5d) also agree on the somewhat more 


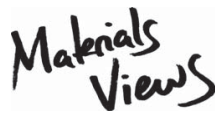

(a)
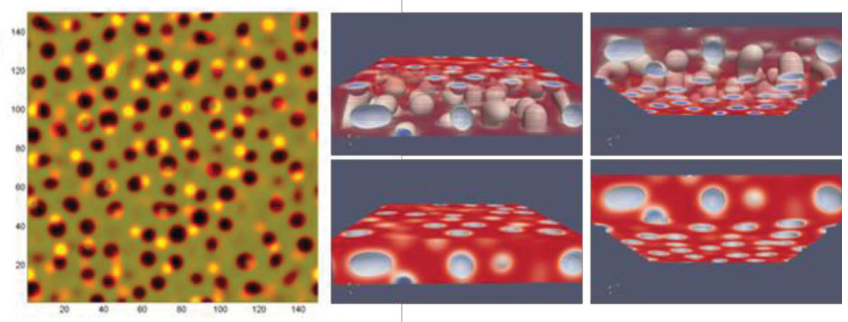

P(VDF-TrFE):F8BT 9:1

$\mathrm{Au}+$ full covered OH-SAM

(b)
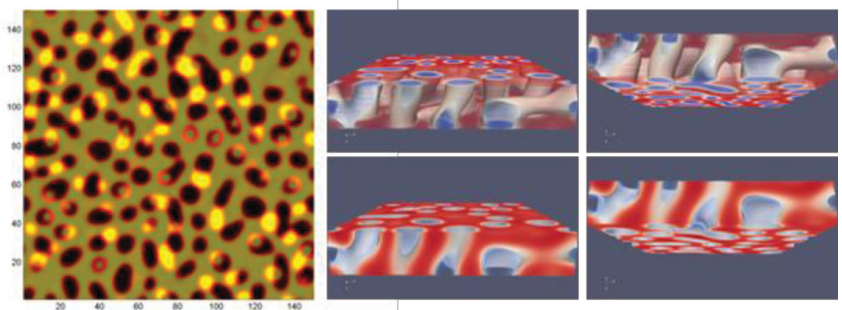

P(VDF-TrFE):F8BT 4:1

$\mathrm{Au}+$ full covered OH-SAM

(c)
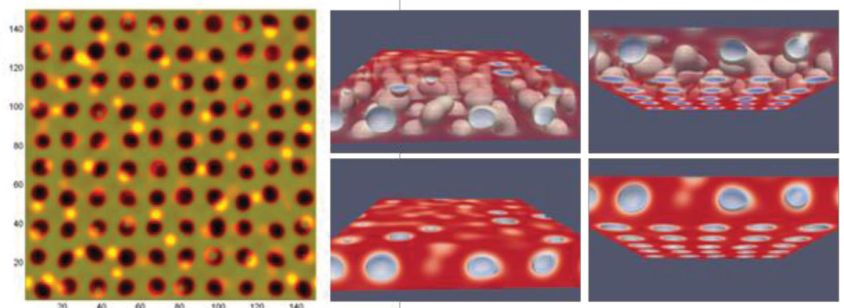

P(VDF-TrFE):F8BT 9:1

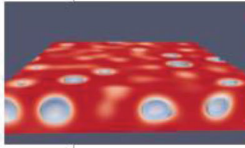

$\mathrm{Au}+$ patterned OH-SAM

(d)
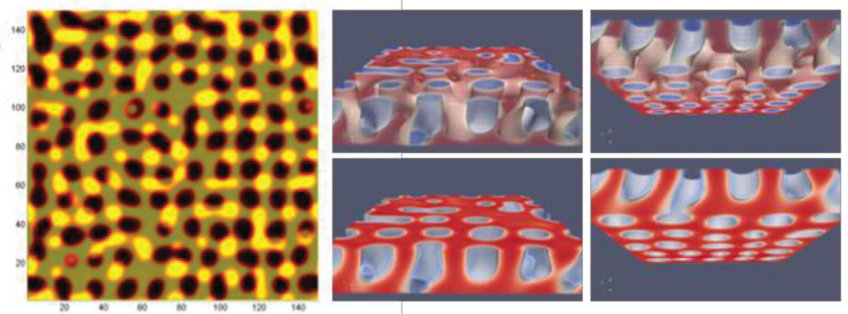

P(VDF-TrFE):F8BT 4:1

$\mathrm{Au}+$ patterned $\mathrm{OH}-\mathrm{SAM}$

Figure 5. Numerical simulation of spinodal decomposition of the P(VDF-TrFE):F8BT blend solution during solvent evaporation on Au electrodes that are a,b) fully and c,d) partially covered with OH-SAM for 9:1 (a,c) and 4:1 (b,d) blend ratios; left panels: overlay of the lateral concentration fields of P(VDF-TrFE) and F8BT at the substrate (dark: F8BT-rich) and air (bright: F8BT-rich) interfaces; right panels: tilted 3D top and bottom view images of the phase separated blend layers: P(VDF-TrFE)-rich (red), F8BT-rich (grey); the same image is shown with a transparent (top) and solid (bottom) matrix phase.

pronounced lateral scrambling of the substrate pattern in case of the 4:1 blend, as compared to the 9:1 blend. In contrast, scrambling of the pattern in the vertical direction is more strongly observed for the 9:1 blend (Figure 4a,5c). The latter observation explains the relatively abundant occurrence of both type- 2 and type-3 F8BT domains in the 9:1 blend layers, at the expense of the desired type- 1 features. Relating to this, the $3 \mathrm{D}$ images in Figure $5 \mathrm{~d}$ clearly show that the features observed at the substrate interface and at the top of the wet film in most cases belong to the same F8BT-rich domains, suggesting a 4:1 blend ratio to eventually yield a larger number of type- 1 domains as compared to patterned films produced from a 9:1 blend. The latter observation is verified by the AFM analysis given in Figure 4 .

Interestingly, the simulations suggest that especially in case of the 9:1 blend F8BT-rich domains can exist that are not in direct contact with either surface (Figure $5 \mathrm{a}, \mathrm{c}$ ). These domains originate from rupture of a preceding stratified phase morphology, induced by surface tension differences between the blend components and/or differences in the time scales of diffusion and evaporation. ${ }^{[34,43]}$ Merging of these encapsulated F8BT droplets with type-2, or -3 domains during later stages of drying is expected to partially account for the occurrence of type-1 F8BT domains. They thus form a very important intermediate state. Direct experimental evidence for the occurrence of these domains in the actual films is difficult to obtain. Because these domains are fully encapsulated by the P(VDF-TrFE)-rich matrix, they do not appear in the AFM measurements of the full blend layer, and they are prone to lift off the substrates upon selective dissolution of the P(VDF-TrFE) matrix.

\subsection{Electrical Characterization of Polymer Blend Films in Memory Switches}

Memory diodes were made by spincoating a continuous $\mathrm{P}(\mathrm{VDF}-\mathrm{TrFE})$ :F8BT film on top of i) gold, ii) gold coated 


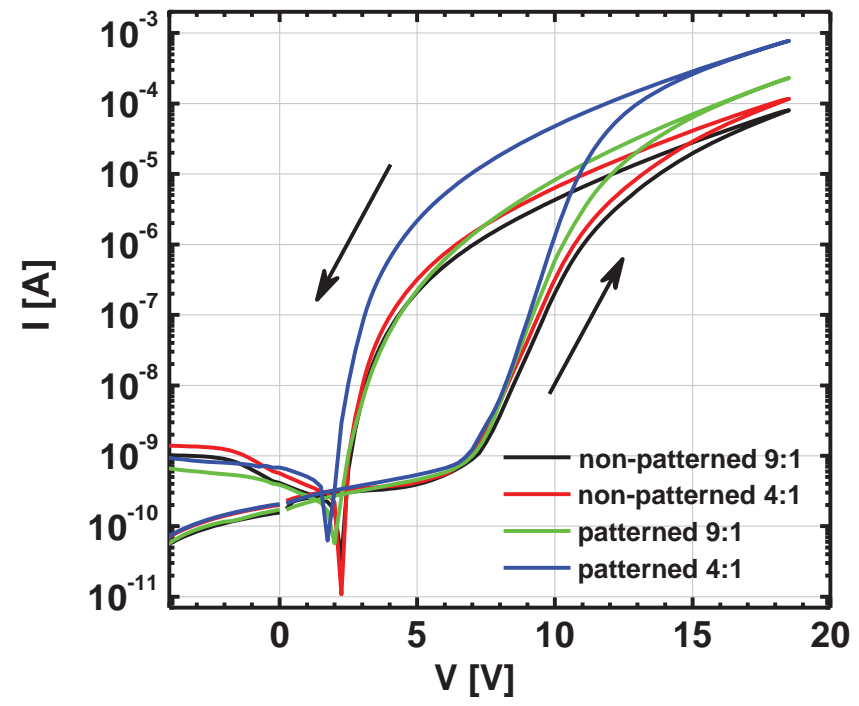

Figure 6. Current vs voltage $(I-V)$ hysteretic sweeps of ferroelectric memory switches fabricated with a P(VDF-TrFE):F8BT 9:1 or 4:1 w/w blend using either a patterned or non-patterned $A u$ anode. In all cases $\mathrm{Ba} / \mathrm{Al}$ is used as cathode. The diode is swept between +18.5 and $-18.5 \mathrm{~V}$. Arrows indicate the scan direction.

with OH-SAM, and iii) gold coated with patterned OH-SAM. $\mathrm{Ba} / \mathrm{Al}$ is used as top electrode in all cases. For unclear reasons all (25) memory diodes made on gold fully covered with OH-SAM were shorted. The typical characteristics of the memory diodes with bare gold and gold coated with patterned OH-SAM are shown in Figure 6. Ferroelectric polarization reversal occurs at ca. $|10| \mathrm{V}$, i.e., close to the coercive electric field of $50 \mathrm{MV} / \mathrm{m}$ measured for $\mathrm{P}(\mathrm{VDF}-\mathrm{TrFE})$ capacitors. ${ }^{[35]}$ The polarization is stable at lower electric fields. Because the perpendicular device current depends on the direction of the polarization state, this state can be read out repeatedly (non-disturb) at lower voltages. This forms the basis for these devices as non-volatile, reprogrammable memories.

As can be seen in Figure 6, the average ON-current of the diode with 9:1 w/w blend and Au electrode (no patterned $\mathrm{OH}$-SAM) is $0.60 \pm 0.04 \mu \mathrm{A}$ at a gate bias of $6 \mathrm{~V}$. The average OFF-current $\left(I_{\mathrm{OFF}}\right)$ is $0.55 \pm 0.01 \mathrm{nA}$. The current modulation $I_{\mathrm{ON}} / I_{\mathrm{OFF}}$, therefore, amounts to 1500 . This value is already relatively high, and allows integration of these diodes in 1 kilobit memory arrays. ${ }^{[11]} I_{\mathrm{OFF}}$ is likely dominated by the leakage currents caused by nonintrinsic effects like slow depolarization and ionic movement, and seems to be independent of both the P(VDF-TrFE):F8BT ratio and regularity of the semiconducting domain pattern. Relative to the 9:1 blend diodes with Au electrodes, 9:1 w/w diodes with patterned OH-SAM as well as $4: 1 \mathrm{w} / \mathrm{w}$ diodes with no OH-SAM have a similar value for $I_{\mathrm{ON}}$, and therefore similar $I_{\mathrm{ON}} / I_{\mathrm{OFF}}$ modulation. The $I_{\mathrm{ON}}$ of the 4:1 w/w diode with patterned OH-SAM increases nearly one order of magnitude. Table 2 shows the mean value of $I_{\mathrm{ON}}$ and the ON to OFF current ratio $\left(I_{\mathrm{ON}} / I_{\mathrm{OFF}}\right)$ measured at a bias of $+6 \mathrm{~V}$ over 25 memory diodes of each type. These results can be correlated to the number density and average size of electrically active type-1 F8BT domains. Except for the 4:1 w/w diode with patterned OH-SAM, the type-1 F8BT domains have a low density (14-27 per $100 \mathrm{\mu m}^{2}$ ). Furthermore, the semiconductor
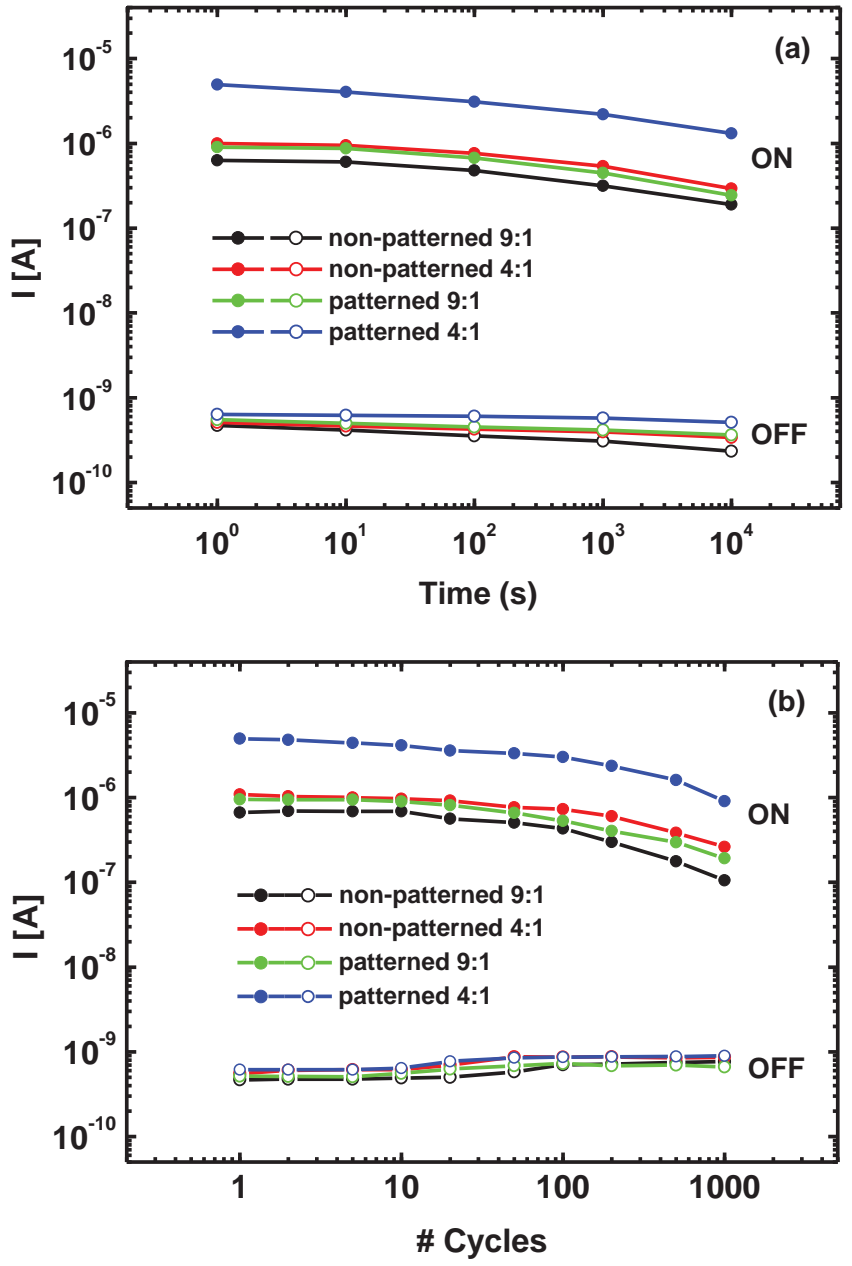

Figure 7. a) Data retention: Evolution of current in the ON state and OFF state as a function of time after programming at a bias of $+6 \mathrm{~V}$. b) Endurance data: Reversible ON and OFF switching - for 1000 consecutive program-erase cycles, readout at $+6 \mathrm{~V}$.

domain diameter of $4: 1 \mathrm{w} / \mathrm{w}$ diodes with no OH-SAM of $2000 \mathrm{~nm}$ is undesirably large. Therefore, a similar $I_{\mathrm{ON}}$ is expected in a zero-order approximation for these diodes. The type-1 F8BT domain number density in case of the $4: 1 \mathrm{w} / \mathrm{w}$ diode with patterned OH-SAM reaches an almost maximum number density per $100 \mu^{2}$. This high density is combined with an average lateral domain size of $\approx 600 \mathrm{~nm}$ because demixing is largely directed by the applied $\mu \mathrm{CP}$ SAM pattern. As a result, a close to 10 -fold increase of the ON-current and a sixfold larger current modulation was found in memory diodes with geometrically controlled phase separation.

Data retention was examined by programming the device once to the ON or OFF state by applying a +18.5 and $-18.5 \mathrm{~V}$ pulse respectively, and then monitoring the current over time at $+6 \mathrm{~V}$ (Figure 7a). All memory devices show excellent retention. Both $I_{\mathrm{ON}}$ and $I_{\mathrm{OFF}}$ do not change more than a factor of 3, effectively resulting in a $I_{\mathrm{ON}} / I_{\mathrm{OFF}}$ ratio of three orders of magnitude after $10000 \mathrm{~s}$. We see no significant differences in current over time for the different memories. Because of its higher initial ONcurrent the 4:1 patterned devices proved to have the highest $I_{\mathrm{ON}} / I_{\mathrm{OFF}}$ ratio of 1800 after $10000 \mathrm{~s}$. 
In Figure $7 \mathrm{~b}$ the low conductance OFF state and high conductance ON state are measured, while the memory device is repeatedly switching between $\mathrm{ON}$ and OFF state by applying program and erase pulses of $\pm 18.5 \mathrm{~V}$. All memory diodes show reversible switching over many cycles. After 1000 cycles an $I_{\mathrm{ON}} / I_{\mathrm{OFF}}$ ratio of over $10^{3}$ is obtained for the $4: 1 \mathrm{w} / \mathrm{w}$ diode with patterned OH-SAM.

\section{Conclusions}

In summary, we have studied in detail the polymer phase separation of $\mathrm{P}(\mathrm{VDF}-\mathrm{TrFE})$ :F8BT blends. Its morphology is key to the operation and performance of memory diodes. Selective dissolution of the individual blend components in combination with AFM analysis showed that only a limited fraction of the semiconductor domains are electrically active. In addition, a semi-continuous, thin $(<40 \mathrm{~nm})$ wetting layer of F8BT was found in case of a reference gold electrode. The specific coordinative interaction between F8BT and gold has been utilized to allow for adsorption of the semiconductor onto designated areas by geometrically controlled monolayer passivation of the gold substrate prior to casting of the P(VDF-TrFE):F8BT blend solutions. Tuning of the P(VDF-TrFE):F8BT blend ratio resulted in a further optimization of the morphology by maximizing the number of electrically active semiconducting domains. Thus, size, position and number density of these domains closely replicated the underlying chemical pattern induced by microcontact printing.

Full 3D numerical simulation of the surface-controlled demixing process has provided insight in the ability of the substrate pattern to direct the phase separation, and hence the regularity of the domain pattern in the final dry blend layers.

The electrical performance of memory diodes could be significantly improved by blend patterning and composition optimization. A close to 10 -fold increase of the ON-current and sixfold larger current modulation was found for memory diodes in which the number density of electrically active domains was maximized by morphology control. Hence, the general concept shown here provides a basis to satisfy the demand of improved functionality and further miniaturization of these memory diodes to smaller feature size and/or higher integration density.

\section{Experimental Section}

Poly[(9,9-di-n-octylfluorenyl-2,7-diyl)-alt-(benzo[2, 1,3]thiadiazol4,8-diyl)] (F8BT) ( $\left.M_{\mathrm{w}}=4.9 \mathrm{kDa}, D=1.8\right)$ was synthesized by Holst Centre/TNO according to a modified Suzuki-polymerization. ${ }^{[36,37]}$ The ferroelectric polymer, Poly(vinylidene fluoride-co-trifluoro ethy- lene) $(\mathrm{P}(\mathrm{VDF}-\mathrm{TrFE}))\left(M_{\mathrm{w}}=220 \mathrm{kDa}, 2.3<D<2.8\right.$ with a $77 / 23 \mathrm{VDF} / \mathrm{TrFe}$ ratio) was supplied by Solvay Specialty Polymers. Blend solutions were prepared by co-dissolving P(VDF-TrFE) and F8BT (9:1 or 4:1 weight ratio) in a mixture of cyclohexanone and tetrahydrofurane 75:25 (v/v) at $50{ }^{\circ} \mathrm{C}$ overnight. Cleaned glass substrates with litho patterned gold were used. Blend films were then spin-coated in a nitrogen-filled glove box. The thickness of the film was measured with a DEKTAK profilometer and varied between 200-230 nm. Subsequently, the samples were annealed at $135^{\circ} \mathrm{C}$ for $5 \mathrm{~min}$. Finally, the $\mathrm{BaAl}$ cathode is evaporated through a shadow mask, followed by thin film encapsulation. Surface topography of the dried blend films was examined by atomic force microscopy. Topography is measured using a sharp (apex radius $<10 \mathrm{~nm}$ ) AFM tip in tapping-mode (TM). The AFM measurements were performed using Al coated Si tips (Nanosensors, spring constant $k \approx 12.5 \mathrm{~N} / \mathrm{m}$ ).

Contact angle measurements were performed at room temperature $\left(22^{\circ} \mathrm{C}\right.$ ) on an Easydrop Standard (Krüss) goniometer using a drop size of $2 \mu \mathrm{L}$. Surface-directed phase separation of semiconductor ferroelectric polymer blend films using the microcontact printing technique was performed on patterned UV-ozone cleaned gold electrodes. A h-poly(dimethylsiloxane) PDMS stamp, featuring a 2D pillar grid of $475-565 \mathrm{~nm}$ wide dots with $1000 \mathrm{~nm} \pm 3 \%$ pitch, was used. Stamps were inked by immersing them in 11-mercapto-1-undecanol solution (1 $\mathrm{mm}$ in ethanol) for about $10 \mathrm{~min}$. After removal from the ink solutions, all stamps were rinsed with ethanol and dried in a stream of nitrogen for about $30 \mathrm{~s}$. Stamping was performed manually for $20 \mathrm{~s}$ by using tweezers for stamp handling and by taking advantage of the natural stamp-substrate adhesion. No extra pressure was applied. A blend of P(VDF-TrFE): F8BT:TFB (9:1 or 4:1 weight ratio) in a mixture of cyclohexanone and tetrahydrofurane 75:25 (v/v) was then spin-coated in a nitrogen-filled glove box onto this patterned surface at $2500 \mathrm{rpm}$ for $60 \mathrm{~s}$ and subsequently annealed for $5 \mathrm{~min}$. at $135^{\circ} \mathrm{C}$.

Fluid phase spinodal de-mixing of the solvent/P(VDF-TrFE)/F8BT blend under evaporative conditions is modeled by a Cahn-Hilliard Cook-deGennes type square gradient approximation, ${ }^{[38-40]}$ involving a ternary Flory-Huggins local mixing free energy. ${ }^{[41,42]}$ The usual bulk free energy functional comprising local and non-local contributions is augmented with terms describing the interaction between the blend components and the substrate- and air interfaces as effective interaction parameters ${ }^{[43]}$ adopting non-zero values only at, respectively, $z=0$ and $z=h$. Solvent evaporation is treated according to a previously published procedure, ${ }^{[4]}$ which at each time step calculates an instantaneous global evaporation rate based on a (relative) mass transfer coefficient and the mean volume fraction of solvent in the top of the fluid layer. The mass loss due to evaporation is then compensated for by downscaling the grid spacing in the $z$-dimension. ${ }^{[45]}$ The model does not take the final stages of drying into account. The input parameters for the simulations are summarized by the tables shown in the supplementary info. Table S1 (SI) lists the Flory-Huggins parameters (i.e., effective degree of polymerization $N_{i}$ and mutual interaction parameter $\chi_{i j}$ ), whereas Table S2 (SI) gives the air and substrate interaction parameters. The effective degrees of polymerization are obtained by scaling the average molar volume of the polymers to that of the solvent (cyclohexanone). Solvent-polymer interaction parameters $\chi_{1 j}$ are chosen to comply with the constraint of compatibility with both polymers $\left(\chi_{1 j}<0.5\right)$, whereby it is assumed that P(VDF-TrFE) is somewhat better soluble than F8BT $\left(\chi_{13}<\chi_{12}\right)$. Polymer-polymer interaction parameter $\chi_{23}$ is taken sufficiently high so as to avoid the formation of mixed binodal phases, that is, in agreement with experimental findings. ${ }^{[13]}$ Surface interaction parameters $\chi_{i}^{a}$ and $\chi_{i}^{s}$ are quantified via the method explained in another study ${ }^{[43]}$ involving the measured disperse $\left(\gamma^{d}\right)$ and polar $\left(\gamma^{p}\right)$ surface energy contributions of the blend components and the substrate (see Table 1). As mentioned, the coordinative interaction between F8BT and $\mathrm{Au}$ cannot be defined by the method of surface energy measurement. Instead, a highly negative (attractive) value of $\chi_{2}^{s}=-200$ is assumed to model the coordination. The choice of this number is admittedly arbitrary, but its exact value is not influencing the outcome of the simulations on a qualitative level.

The data in Table S2 (SI) allows computational reproduction of the experimental dot-pattern in the Au substrate passivation by the microcontact printed $\mathrm{OH}-\mathrm{SAM}$ by assigning the $\chi_{\mathrm{i} \text {-Au }}^{\mathrm{s}}$ and $\chi_{\mathrm{i}-\mathrm{OH}}^{\mathrm{S}}$ parameters for each blend component to specified clusters of elements on a periodic $2 \mathrm{D}$ grid which functions as the substrate in the $3 \mathrm{D}$ simulations. 100- or 25-fold replication of the single-dot unit cell in a square geometry is respectively implemented on a $150 \times 150$ or $75 \times 75$ grid. At the air interface the surface tension for each pure component is represented isotropically by $\chi^{\mathrm{a}} \cdot{ }^{[43]}$ 


\section{Supporting Information}

Supporting Information is available from the Wiley Online Library or from the author.

\section{Acknowledgements}

The authors would like to thank Alessio Marrani from Solvay Specialty Polymers, Italy for providing the P(VDF-TrFE) material. The research leading to these results has received funding from the European Community's Seventh Framework Program (FP7/2007-2013) under grant agreement $n^{\circ} 248092$ of the MOMA project.

Received: June 10, 2014

Revised: September 12, 2014

Published online: October 29, 2014

[1] J. Smith, R. Hamilton, I. McCulloch, N. Stingelin-Stutzmann, M. Heeney, D. D. C. Bradley, T. D. Anthopoulos, J. Mater. Chem. 2010, 20,2562, and references cited therein.

[2] C. J. Brabec, M. Heeney, I. McCulloch, J. Nelson, Chem. Soc. Rev. 2011, 40, 1185

[3] A. C. Morteani, A. S. Dhoot, J. S. Kim, C. Silva, N. C. Greenham, C. Murphy, E. Moons, S. Ciná, J. H. Burroughes, R. H. Friend, Adv. Mater. 2003, 15, 1708

[4] A. C. Arias, F. Endicott, R. A. Street, Adv. Mater. 2006, 18, 2900.

[5] K. Asadi, D. M. de Leeuw, B. de Boer, P. W. M. Blom, Nature Mater. 2008, 7, 547.

[6] Polymer Blends Handbook, (Ed: L. A. Utracki), Kluwer Academic Publishers, Dordecht 2002

[7] M. Kemerink, K. Asadi, P. W. M. Blom, D. M. de Leeuw, Org. Electronics 2012, 13, 147.

[8] V. Khikhlovskyi, R. Wang, A. J. J. M. van Breemen, G. H. Gelinck, R. A. J. Janssen, M. Kemerink, J. Phys. Chem. C 2014, 11, 3305.

[9] K. Asadi, H. J. Wondergem, R. S. Moghaddam, C. R. McNeill, N. Stingelin, B. Noheda, P. W. M. Blom, D. M. de Leeuw, Adv. Funct. Mater. 2011, 21, 1887.

[10] M. Li, N. Stingelin, J. J. Michels, M.-J. Spijkman, K. Asadi, R. Beerends, F. Biscarini, P. W. M. Blom, D. M. de Leeuw, Adv. Funct. Mater. 2012, 22, 2750.

[11] A. J. J. M. van Breemen, J.-L. van der Steen, G. van Heck, R. Wang, V. V. Khikhlovskyi, M. Kemerink, G. H. Gelinck, Appl. Phys. Expr. 2014, 7, 031602

[12] M. A. Khan, U. S. Bhansali, D. Cha, H. N. Alshareef, Adv. Funct. Mater. 2013, 23, 2145

[13] J. J. Michels, A. J. J. M. van Breemen, K. Usman, G. H. Gelinck, J. Polym. Sci. Part B: Polym. Phys. 2011, 49, 1255.

[14] S. Y. Heriot, R. A. L. Jones, Nat. Mater. 2005, 4, 782.

[15] C. M. Björström, S. Nilsson, A. Bernasik, A. Budkowski, M. Andersson, K. O. Magnusson, E. Moons, Appl. Surf. Sci. 2007, 253, 3906.
[16] R. Hamilton, J. Smith, S. Ogier, M. Heeney, J. E. Anthony, I. McCullogh, J. Veres, D. D. C. Bradley, T. D. Anthopoulos, Adv. Mater. 2009, 21, 1166.

[17] A. Bernasik, J. Wlodarczyk-Miskiewicz, W. Luzny, K. Kowalski, J. Raczkowska, J. Rysz, A. Budkowski, Synth. Met. 2004, 144, 253.

[18] T. Fukuma, K. Kobayashi, T. Horiuchi, H. Yamada, K. Matsushige, Jap. J. Appl. Phys. 2000, 39, 3830.

[19] D. K. Owens, R. C. Wendt, J. Appl. Polym. Sci. 1969, 13, 1741.

[20] D. Y. Kwok, A. W. Neumann, Adv. Colloid Interface Sci. 1999, 81, 167.

[21] F. M. Fowkes, Ind. Eng. Chem. 1964, 56, 40.

[22] C. M. Björström, S. Nilsson, A. Bernasik, A. Budkowski, M. Andersson, K. O. Magnusson, E. Moons, Appl. Surf. Sci. 2007, 253, 3906.

[23] M. Böltau, S. Walheim, J. Mlynek, G. Krausch, U. Steiner, Nature 1998, 391, 877.

[24] K.-H. Yim, Z. Zheng, R. H. Friend, W. T. S. Huck, J.-S. Kim, Adv. Funct. Mater. 2008, 18, 2897.

[25] A. Budkowski, A. Bernasik, P. Cyganik, J. Rysz, R. Brenn, e-Polym. 2013, 2, 88.

[26] G. Fichet, N. Corcoran, P. K. H. Ho, A. C. Arias, J. D. Mackenzie, W. T. S. Huck, R. H. Friend, Adv. Mater. 2004, 16, 1908.

[27] N. Corcoran, P. K. H. Ho, A. C. Arias, J. D. Mackenzie, R. H. Friend, G. Fichet, W. T. S. Huck, Appl. Phys. Lett. 2004, 85, 2965.

[28] L.-M. Chen, Z. Xu, Z. Honga, Y. Yanga, J. Mater. Chem. 2010, 20, 2575.

[29] X. Wang, W. H. Lee, G. Zhang, X. Wang, B. Kang, H. Lu, L. Qiu, K. Cho, J. Mater. Chem. C 2013, 1, 3989.

[30] C. Liu, Y. Li, M. V. Lee, A. Kumatania, K. Tsukagoshi, Phys. Chem. Chem. Phys., 2013, 15, 7917.

[31] J. L. Wilbur, A. Kumar, H. A. Biebuyck, E. Kim, G. M. Whitesides, Nanotechnology 1996, 7, 452.

[32] A. Perl, D. N. Reinhoudt, J. Huskens, Adv. Mater. 2009, 21, 2257.

[33] C. D. Bain, E. B. Troughton, Y.-T. Tou, J. Evall, G. M. Whitesides, R. G. Nuzzo, J. Am. Chem. Soc. 1989, 111, 321.

[34] O. Wodo, B. Ganapathysubramanian, Comput. Mater. Sci. 2012, 55, 113.

[35] T. Furukawa, Phase Trans. 1989, 18, 143.

[36] T. van Woudenbergh, J. Wildeman, P. W. M. Blom, J. J. A. M. Bastiaansen, B. M. W. Langeveld-Voss, Adv. Funct. Mater. 2004, 14, 677 .

[37] N. Miyaura, A. Suzuki, Chem. Rev. 1995, 96, 2457.

[38] J. W. Cahn, J. E. Hilliard, J. Chem. Phys. 1958, 28, 258.

[39] H. E. Cook, Acta Metall. 1970, 17, 297.

[40] P. G. de Gennes, Scaling Concepts in Polymer Physics, Cornell University Press, Ithaca, NY 1979.

[41] P. J. Flory, Principles of Polymer Chemistry, Cornell University Press, Ithaca, NY 1953.

[42] The simulations involve a single solvent rather than a mixture to allow for reasonable computation times. The effect of an actual binary solvent system is outside the scope of this paper.

[43] J. J. Michels, E. Moons, Macromolecules 2013, 46, 8693.

[44] C.-S. Kim, D. M. Saylor, M. K. McDermott, D. V. Patwardhan, J. A. Warren, J. Biomed. Mater. Res. Part B: Appl. Biomater. 2009, 688.

[45] G. A. Buxton, N. Clarke, Eur. Polym. Lett. 2007, 78, 56006. 